\title{
Norte-americanos na Bahia: o projeto civilizador dos missionários presbiterianos
}

\begin{abstract}
RESUMO: Este trabalho analisa a ação civilizadora presbiteriana, procurando compreender a importância da Bahia para os missionários norte-americanos como locus de sua atuação na região sob sua jurisdição. Investiga a importância do Instituto Ponte Nova e do Grace Memorial Hospital para a formação de quadros nos campos da educação, saúde e evangelização, tornando-se um pólo irradiador de um modelo cultural norte-americano.

PALAVRAS-CHAVE: Igreja Presbiteriana. Instituto Ponte Nova - Chapada Diamantina (BA). Missionários - Estados Unidos.
\end{abstract}

A presença de missionários presbiterianos norte-americanos no Nordeste iniciou-se a partir de 1871, na cidade de Salvador. O grupo de missionários enviados pela Junta de Missões da Igreja Presbiteriana do norte dos Estados Unidos, responsável pela implementação do trabalho evangélico e educacional na Bahia, fora o mesmo que atuara em São Paulo a partir de 1859, organizando, além de igrejas, instituições educacionais, das quais, a que mais se destaca tanto na historiografia educacional brasileira como na historiografia protestante, é o Mackenzie College. (NASCIMENTO, 2001)

Uma pesquisa desenvolvida a partir de 1997, sobre a Escola Americana de Sergipe, me levou a perceber que a ação missionária presbiteriana norte-americana naquele Estado era só a ponta de um iceberg. A investigação que resultou numa dissertação de mestrado se propunha a rastrear a primeira escola secundária presbiteriana organizada no Nordeste que se tem notícia, que funcionara entre 1886 e 1913, quase ausente na documentação oficial do Estado e na historiografia educacional sergipana. (NASCIMENTO, 2004)

Wagner, 1905. A fazenda Ponte Nova é comprada pela Missão Central do Brasil na imensidão da Chapada Diamantina e ali será construída uma "ilha" de civilização no "Brasil Tropical"1. Wagner, dois de fevereiro de 2002. Chego numa cidade decadente, que vive da memória dos tempos áureos da presença norte-americana, e me impressiono com os edifícios do Grace Memorial Hospital, da Igreja Presbiteriana de Wagner e do Instituto Ponte Nova,
Ester Fraga Vilas-Bôas Carvalho do Nascimento Professora.da Universidade Tiradentes, Aracaju-SE ester.fraga@uol.com.br
(1) Termo utilizado pelos missionários presbiterianos norte-americanos nos relatórios para se referirem ao interior brasileiro. 
(2) Este trabalho adota o conceito de civilização, de Norbert Elias. Para o Autor, civilização refere-se a uma variedade de fatos que dizem respeito a maneiras, conhecimentos científicos, idéias religiosas, costumes etc. Pode tratar ao tipo de habita- construídos pela Missão Central do Brasil. A cidade tinha-se formado ao redor dos prédios presbiterianos. Na área central, as ruas levavam os nomes de antigos missionários e ex-professoras. As casas acompanhavam o modelo arquitetônico residencial norte-americano, com varandas construídas sob vértices e colunas, além de portas e janelas altas e largas, permitindo a passagem de luz e ventilação, e das características telas de proteção contra mosquitos. Na praça central, que levava o nome do médico e cirurgião presbiteriano Walter Welcome Wood, me deparei com o busto do missionário. Pelo embates religiosos travados entre os norte-americanos e os dirigentes católicos, fora construído um cemitério, atualmente abandonado pela própria igreja presbiteriana, dentro da antiga fazenda Ponte Nova, onde encontrei os túmulos de Grace Brown Wood e Mabel Oliver Wood, mulheres do médico, falecidas por haverem contraído doenças tropicais. (NASCIMENTO, 2005a)

$\mathrm{Na}$ avenida principal da cidade, que também leva o nome do médico norte-americano Walter Welcome Wood, encontram-se a Igreja Presbiteriana de Wagner e o Grace Memorial Hospital. Disposto em três pavilhões, o hospital fora construído em forma de "T" onde funcionara a Escola de Enfermagem, as residências dos médicos e enfermeiras, a clínica e a área de cirurgia.

Caminho mais um pouco e avisto o rio Utinga, que separa a cidade da escola. Atravesso a ponte e conheço a área em que foi construído o Instituto Ponte Nova e o que restara do seu complexo escolar: o antigo sobrado, onde funcionara a primeira residência dos missionários e o internato feminino; os três pavilhões de salas de aula, com uma área central coberta para recreação e a biblioteca; a antiga praça de esportes, já desativada; o Auditório James Wright; o terreno do antigo internato masculino que foi derrubado para dar lugar à atual Escola Agrotécnica Afrânio Peixoto, instituição secundária estadual; e o internato feminino, construção vitoriana de dois pisos, equipado com lavanderia, padaria e despensa. Um pouco mais afastada estava a área onde os alunos recebiam aulas práticas de técnicas agrícolas e de criação de aves e porcos.

O projeto civilizador ${ }^{2}$ presbiteriano para o hinterland brasileiro possuía três eixos de ação: religião, educação e saúde. Criando instituições nas três áreas, os mensageiros de Deus, pretendiam transformar o hinterland brasileiro numa região "civilizada", pro- 
curando produzir um novo modo de viver na sociedade $\mathrm{em}^{3}$ que se estabeleceram. E a educação serviria de veículo para a implementação de sua proposta.

Dentre as várias estratégias que os mensageiros de Deus se utilizaram, procurando produzir um determinado projeto de ordenação espacial e de imposição de novos modos de viver, este trabalho se detém especialmente nas iniciativas que visaram fazer da educação escolar um meio de civilizar a população que abrangia a área sob sua jurisdição. Trata-se mais especificamente de interrogar acerca das representações e práticas que configuraram o programa de educação secundária proposto pelo Instituto Ponte Nova e, ao mesmo tempo, em atentar para os múltiplos dispositivos, por intermédio dos quais procurou-se divulgar, dentro e fora da escola, os preceitos de sua considerada moderna educação àqueles que estavam sob seu raio de ação. Criado pela Missão Central do Brasil, em conformidade com os moldes educacionais presbiterianos norte-americanos, o Instituto Ponte Nova teve papel fundamental na formulação da política de ação daquela organização missionária. Política que tinha como objetivo formar professoras para suas escolas e homens que seriam evangelistas e futuros pastores de suas igrejas, transformando-os em agentes de uma nova proposta civilizatória. (NASCIMENTO, 2005b)

Os mensageiros de Deus eram missionários que geralmente tinham se formado nos grandes centros teológicos do norte dos Estados Unidos (Princeton, Harvard e Yale) ou nos do sul (Vanderbilt e Richmond) e eram portadores de um "protestantismo de civilização", "convencidos de que possuíam as chaves da modernidade religiosa e econômica". O missionário foi o "agente propagador dos modelos protestantes na América Latina", importante "na transmissão de modelos organizativos importados, e na apresentação, em seu país de origem, da realidade latinoamericana". Apresentava-se como representante de uma cultura mais adiantada, civilizada. Aquele indivíduo podia ser um pastor, um médico, um enfermeiro, um professor, como também uma missionária, uma enfermeira ou uma instrutora (BASTIAN, 1994, p. 111-112) ções ou à maneira como homens e mulheres vivem juntos, ou como são preparados os alimentos. A civilizacão diz respeito às regularidades, o que é comum a todos os homens. (ELIAS, 1994)

(3) Este trabalho entende sociedade como uma rede de funçōes

interdependentes no interior das associações humanas pela qual as pessoas estão ligadas entre si que, apesar de não serem visíveis ou tangíveis, são reais. E o homem, dentro dessa configuração social passa por um processo civilizador individual que é função do processo civilizador social. O resultado do contato contínuo com a experiência produz o que Elias denomina de condição humana. (ELIAS, 1994) 


\section{A construção do espaço urbano de Wagner}

Quando os missionários presbiterianos norte-americanos se instalaram na fazendaPonte Nova, a partir de 1906, existiam outras fazendas e algumas casas esparsas naquela região. Em menos de duas décadas surgira um aglomerado urbano que, apesar de ter dimensões modestas, apresentava marcas da cultura norte-americana. A imagem de uma "ilha" norte-americana, produzida pelos missionários, com seus hábitos e costumes, vai configurando a identidade da futura cidade, rompendo com antigas tradições. A construção de prédios monumentais, a abertura de novas vias de circulação produzindo um traçado urbano, possibilitariam uma intensa circulação entre aquela cidade e outras regiões.

No interior da Chapada Diamantina, sob os auspícios da Missão Central do Brasil, a estação missionária, planejada e fundada por William Alfred Waddell, pretendia dominar e civilizar seu entorno, evangelizando e educando, salvando o corpo, a mente e o espírito de moradores da região. Para William Alfred Waddell, o complexo seria uma fronteira civilizadora no "Brasil tropical", compondo seu anel de poder através dos missionários que também eram administradores, educadores, engenheiros, médicos e enfermeiras.

Antigo centro produtor de arroz, açúcar mascavo, rapadura e aguardente, o município de Wagner está localizado na Chapada Diamantina Meridional, distante $384 \mathrm{~km}$ de Salvador, e $65 \mathrm{~km}$ de Lençóis. O nome da cidade homenageia o engenheiro alemão Franz Wagner pelos serviços prestados à população durante a seca que assolou o Nordeste no final da década de 1880. A partir de sua fazenda, foram surgindo outras fazendas, dando origem a um núcleo populacional que ficou conhecido por Cachoeirinha, às margens do rio Utinga, embrião do futuro município. Posteriormente, seus moradores fizeram um requerimento à Câmara $\mathrm{Mu}$ nicipal de Morro do Chapéu solicitando a mudança de Cachoeirinha para Wagner, o qual foi atendido, em 8 de abril de 1891.

Dando visibilidade ao seu projeto civilizador, durante décadas, a Missão Central do Brasil investiu na construção de edifícios para suas instituições - escola, igreja e hospital. Apesar da

decadência atual da cidade, ainda hoje é possível verificar a 
monumentalidade destas construções, tendo em vista o cenário local. A primeira construção realizada por William Alfred Waddell, provavelmente no ano de 1907, foi a Igreja Presbiteriana de Wagner, chamada inicialmente de Egreja Christã Presbyteriana de Ponte Nova. O terreno escolhido para construir a igreja ficava na margem esquerda do rio Utinga, numa área alta e salubre da fazenda.

A presença dos missionários presbiterianos imprimira um modelo arquitetônico às residências que ficavam próximas aos seus prédios ${ }^{4}$. O espaço urbano ocupado pela Missão demonstrava uma forma social organizada por aqueles indivíduos. Era possível verificar a presença da ordem social presbiteriana norte-americana para a realidade física do centro urbano de Wagner através das linguagens simbólicas de sua cultura.

No centro urbano de Wagner pode-se ler uma simbologia através de uma nomenclatura que manifesta a presença daquele grupo religioso. A principal avenida da cidade chama-se Avenida 12 de Agosto, em comemoração à chegada do primeiro missionário presbiteriano norte-americano ao Brasil, e ao início do funcionamento do Instituto Ponte Nova. A rua Régis recebeu esta denominação em homenagem ao abastado casal presbiteriano Floriano e Carmélia Regis, vindo da cidade de Campo Formoso. Na casa em que moravam, tinha um pomar aos fundos; na frente, um grande jardim e, ao lado, uma quadra de esporte, balanços e gangorras. A rua Dalila Costa foi uma homenagem a uma professora sergipana do Instituto Ponte Nova quando ainda era viva. A rua Samuel Graham registra o nome de um missionário norteamericano, ex-diretor do Instituto Ponte Nova. A rua Américo Chagas, do médico baiano, presbiteriano, que também trabalhara no Memorial Hospital, em Wagner. A rua Ponte Nova, em homenagem ao Instituto Ponte Nova.

\section{Práticas educacionais como práticas civilizatórias no Instituto Ponte Nova}

O Instituto Ponte Nova foi a primeira instituição de ensino secundário, rural, da Missão Central do Brasil funcionando como pólo irradiador de professoras e futuros pastores presbiterianos na região sob sua jurisdição, visto pelos seus fundadores como instrumentos de civilização dos sertões através das escolas e igre-
(4) Segundo Viñao Frago e Escolano (1998, p. 28), "não apenas o espaço-escola, mas também sua localização, a disposição dele na trama urbana dos povoados e cidades, tem de ser examinada como um elemento curricular. A produção do espaço escolar no tecido de um espaço urbano determinado pode gerar uma imagem da escola como centro de um urbanismo racionalmente planificado ou como uma instituição marginal e excrescente". 
(5) Para Bastian (1994, p. 107), o protestantismo norte-americano, que se secularizava, se preocupava não somente em inculcar ritos $\mathrm{e}$ dogmas, mas, acima de tudo, "um estilo de vida moral cujos principais signos 'cristãos' tangiveis eram a leitura da Bíblia, a abstenção do álcool e do fumo, o respeito ao descanso dominical, a proibição dos jogos de azar e a defesa da monogamia". jas dirigidas por eles. A escola legitimaria novas concepções no campo da educação, articuladas a novas estratégias de intervenção sobre o hinterland e seus habitantes, introduzindo mudanças de comportamento naqueles que seriam seus alunos.

Entendendo que as práticas educacionais são fundamentalmente práticas civilizatórias que abrangem os âmbitos econômico, religioso, político, moral técnico e social, a representação construída pela denominação presbiteriana era que nos seus estabelecimentos educacionais o ensino era administrado por educadores de "elevados espíritos" e a moral era "evangélica, sem as imposições religiosas de certos colégios, onde não se passa nos exames uma vez que não se tenha o jeito de aparentar fé, nem facilidades de autômato para genuflexões e êxtases pias". Seus edifícios escolares também eram representações importantes da ordem, da boa convivência, do respeito mútuo. A divisão espacial deveria proporcionar uma distribuição estratégica dos alunos, pois, apesar de suas escolas oferecerem o ensino misto, os internatos os separavam.

Desde a sua fundação, o Instituto Ponte Nova adotou alguns princípios que nortearam toda a organização dos seus cursos, tornando-se pilares sobre os quais estava assentada a base da educação difundida pelos missionários presbiterianos da Junta de Nova Iorque. Os sinais tangíveis ${ }^{5}$ da cultura presbiteriana estavam presentes na educação oferecida por este educandário. A educação ministrada estava alicerçada nos princípios da moral cristã, exemplificados por Cristo e inscritos na Bíblia. Compreendiam que o homem tem corpo e mente, "porém é uma alma" e todo esforço deveria ser feito para "num ambiente cristão, possa o aluno desenvolver o seu caráter que consideramos - a saúde da alma".

Esta escola pretendia formar e instruir o cristão verdadeiro, ou seja, o homem bom e honesto, que tivesse objetivos elevados e levasse uma vida pura e, com persistência, defendesse sempre a verdade, esta baseada na Palavra de Deus. Oferecia uma educação integral, ou seja, a formação intelectual, moral e espiritual de homens e mulheres tementes a Deus, bem instruídos e disciplinados, amantes da liberdade. Além de cristãos verdadeiros, seriam cidadãos participantes da vida civil e política do seu país, construtores de uma sociedade democrática, moderna e progressista, semelhante à sociedade norte-americana. E esses princípi- 
os estavam explicitados no lema da escola: "Deus e Pátria aqui sempre lembrados".

Para atingir esse objetivo, o Instituto Ponte Nova oferecia o ensino da doutrina cristã baseado na leitura diária da Bíblia, procurando incutir nos alunos os princípios do cristianismo e que estes fossem colocados em prática no dia-a-dia. A leitura e o estudo da Bíblia, o canto de hinos e orações, bem como a assistência de todos os alunos aos atos religiosos da igreja presbiteriana local, faziam parte do currículo e do regulamento interno da instituição.

Para instruir e formar a juventude, a instituição procurava formar educadoras cristãs, professoras com espírito missionário, e futuros pastores devotados, capazes de suportar certo grau de auto-sacrifício, colocando sua tarefa salvadora acima de qualquer dificuldade. A escola seguia métodos norte-americanos adaptando-os às condições existentes, pois seus dirigentes entendiam que o bom educador não poderia ter idéias preconcebidas e fixas, mas cultivar uma mente aberta, para além das teorias, escolhendo o que fosse melhor para o aluno e a sociedade em que vivia.

A educação para ambos os sexos, considerada uma inovação, fora uma prática utilizada pelos missionários presbiterianos nas escolas que instituíram. George W. Chamberlain, em 1885, justificava a co-educação por ter Deus instituído a família, "dando-lhe filhos e filhas" e a escola deveria ser "o reflexo da constituição divina". Vinte e nove anos depois, William Alfred Waddell, diretor da Escola Americana de São Paulo e fundador do Instituto Ponte Nova, reafirmava aquele procedimento metodológico, informando que até aquele momento, a escola não tivera nenhum "incidente desagradável". (LAGUNA, 1999, p. 210)

Os embates que ocorriam entre católicos e protestantes foi um elemento que facultou o aparecimento não somente daquela instituição, mas de todas as escolas que os missionários presbiterianos organizaram na área sob sua jurisdição. O Instituto Ponte Nova ofereceu educação não somente aos alunos protestantes mas alunos de todos os credos que desejavam nele estudar, reforçando a posição de grupos progressistas da sociedade baiana, pois o ensino ali ministrado pautava-se na construção de uma sociedade moderna, democrática, na qual os indivíduos ali formados eram doutrinados à liberdade de consciência, de crítica e de discussão, princípios estes vinculados ao protestantismo. 
(6) Walter Welcome Wood nasceu em 8 de setembro de 1883, na Califórnia. Era médico-cirurgião, formado em 1915, pela Lelland Stanford University, Califórnia. O Dr. Walter Welcome Wood chegou ao Brasil em 1916 e três anos depois, revalidou seu diploma na Faculdade de Medicina da Bahia, defendendo tese em Medicina Geral, Cirurgia, Obstetrícia e Oftalmologia. Foi o primeiro médico missionário da Igreja Presbiteriana do Norte dos Estados Unidos, enviado para a América do Sul. Em 1922, fez especialização em medicina tropical, na London School of Tropical Medicine.

(7) Em 1922, Grace Brown Wood faleceu. Naquele mesmo ano, o Dr. Walter Welcome Wood casou-se, pela segunda vez, com Mabel Oliver Wood, a qual viria a falecer em Wagner, no dia 6 de junho de 1931.
O Instituto era apresentado pela denominação presbiteriana como uma importante instituição educacional voltada para a formação do caráter do indivíduo. As professoras ali formadas que dirigiriam ou lecionariam em outras escolas, tinham "uma esplêndida oportunidade para trabalhar pelo futuro de sua pátria, incutindo nos corações dos futuros homens e mulheres do País os ideais do patriotismo e, além das quatro operações, as boas maneiras e o amor ao trabalho." (O PURITANO, $1^{\circ}$ de agosto de 1907)

\section{Higienizar, sanear, curar... A ação na área da saúde}

Em 1916, chegara à Estação Ponte Nova o médico e cirurgião Walter Welcome Wood com sua primeira esposa, a enfermeira Grace Brown Wood ${ }^{6}$, para atuarem na estação missionária de Ponte Nova. Logo que chegou, abriu um ambulatório e uma farmácia, construídas com adobe, 50 metros adiante da igreja. Quatro anos depois, a Junta de Nova Iorque deu-lhe permissão para comprar material e equipamentos hospitalares, construir o prédio do hospital, a casa do médico e duas casas para enfermeiras. Sob a direção do Dr. Walter Welcome Wood, a Missão solicitou ao Departamento de Engenharia Sanitária do Mackenzie College planos para drenagem das terras de Ponte Nova, para deter a febre amarela e a malária que assolavam a região. (CENTRAL BRAZIL MISSION, 1938)

Durante o ano de 1924, ainda com um equipamento inadequado do antigo hospital e dispensaria, Dr. Walter Welcome Wood e da enfermeira missionária Lydia Hepperle, treinaram algumas alunas do Instituto Ponte Nova como enfermeiras para se juntarem ao seu staff, tratando de 14.753 pacientes, fazendo 250 operações, num total de 92 pacientes atendidos por dia, e 1.886, por mês. (WHEELER, 1926, p. 300-302). Dois anos depois, foram construídos os prédios definitivos do hospital, denominado Grace Memorial Hospital, em homenagem à sua primeira esposa, falecida em Wagner, em 21 de junho de $1922^{7}$. O primeiro hospital da região da Chapada Diamantina oferecia os seguintes serviços, distribuídos em quatro pavilhões: clínica médica, cirurgia, obstetrícia, pediatria, ginecologia, urologia, Raio-X, diatermia e laboratório. (UNITED STATES OF AMERICA, 1936)

O hospital possuía enfermarias masculina e feminina, apartamentos particulares, sala de parto e de cirurgia. Os banheiros, a 
lavanderia e a cozinha ficavam num prédio em separado. Havia também uma área destinada ao isolamento para doenças infectocontagiosas. O gabinete médico-biométrico, instalado no Grace Memorial Hospital, possuía o seguinte aparelhamento: uma balança, aparelho para mediar a estatura, outro para medir a pressão arterial, além de fichas médico-biométricas ${ }^{8}$. (UNITED STATES OF AMERICA, 1936)

O relatório informava que o curso fora dimensionado às necessidades locais com os seguintes objetivos: formar e educar moças brasileiras, formando enfermeiras disseminadoras do modelo higiênico e sanitário presbiteriano norte-americano. Além de serem exemplos de vida saudável, as novas profissionais organizariam e dirigiriam ambulatórios clínicos em locais fora da Estação Missionária Ponte Nova, que não existissem médicos. Ensinariam princípios de higiene, alimentação e cuidado com as crianças, dando ênfase ao pré-natal. O curso de enfermagem era compreendido pela Missão como um ministério no qual, a instrução bíblica e a manutenção de serviços devocionais regulares estavam incluídas, formando enfermeiras "missionárias". (CENTRAL BRAZIL MISSION, 1938)

Sob a direção do Dr. Walter Welcome Wood, o Grace Memorial Hospital foi o único núcleo hospitalar presente no interior da Bahia durante muitos anos, atraindo pacientes tanto da capital como de outros Estados. Os doentes vinham a pé, de mula, em carroças ou em pequenos carros e, muitas vezes, se convertiam, tornando-se membros da Igreja Ponte Nova. Uma prática recorrente no hospital era a leitura da Bíblia. Havia um exemplar na sala de espera e, às vezes, ficava uma pessoa lendo em voz alta alguns trechos, possibilitando os presentes ouvirem.

As principais moléstias tratadas ali eram pneumonia, malária, úlceras tropicais, sífilis, tuberculose, parasitas intestinais, e tumores. Muita superstição estava vinculada ao nascimento de crianças. Os hábitos alimentares presentes naquelas áreas rurais dificultavam as mães em nutrirem e criarem seus filhos, pois "muitas delas comiam carne ao invés de se alimentarem de vegetais e frutas".A experiência vivenciada pelo Dr. Walter Welcome Wood na estação missionária levou-o a sugerir que os seminários teológicos no Brasil precisavam oferecer cursos simples, de medicina preventiva, higiene pessoal e sanitária, e dieta para que os futuros ministros estivessem preparados para enfrentar os pro-
(8) Apesar de alguns trabalhos produzidos por ex-alunos da instituição afirmarem que a Escola de Enfermagem foi organizada em 1926, os livros de atas da Missão Central do Brasil registram sua organização em abril de 1931, sob a direção de Lydia Hepperle. Em 1961, recebeu o registro federal de funcionamento. passando a chamar-se Escola Auxiliar de Enfermagem Ponte Nova. Em 1971, quando da Missão Central do Brasil retirou-se da Bahia, seu arquivo foi recolhido para a Secretaria de Estado da Educação, em Salvador. 
(9) Em 1933, o Dr. Walter Welcome Wood casou-se com Ella Mary Dahmes, com quem teve cinco filhos. blemas rurais de saúde. Ele também enfatizou a importância de treinar mulheres que trabalhassem com os problemas da casa e do cuidado com as crianças.

Em 1954, o Dr. Walter Welcome Wood e sua terceira esposa, a enfermeira Ella Mary Dahmes Wood, retornaram aos Estados Unidos ${ }^{9}$. Anos depois de sua saída, a memória daquele médico foi perpetuada com o seu busto erigido em 1976, na praça principal de Wagner, com a seguinte legenda: "Dr. W. W. Wood, médico e cirurgião norte-americano, que dedicou a sua vida ao povo do sertão da Bahia, fazendo da medicina um sacerdócio em benefício da humanidade sofredora".

Outro problema enfrentado por aqueles missionários era a falta de um sistema de transporte para aquela região, dificultando o acesso à estação Ponte Nova. Para ampliar o seu raio de ação, a Missão organizou juntamente com o governo baiano, provavelmente em 1925, a Empresa de Estrada e Rodagem Progresso Rodoviário, a qual teve como presidente durante alguns anos o missionário Dr. Walter Welcome Wood. Sob sua direção, foi construída uma estrada ligando Ponte Nova a Itaeté. No mesmo período, também foi construída uma estrada ligando Wagner a Lençóis. (CENTRAL BRAZIL MISSION, 1938)

\section{Considerações finais}

Como foi constatado pela pesquisa realizada, são quase inexistentes os estudos que se dedicam a investigar a ação presbiteriana no hinterland brasileiro e a importância do Instituto Ponte Nova na formação de quadros que dessem continuidade ao seu projeto civilizador. O livro de atas da Missão Central do Brasil foi decisivo na decifração das representações, discussões, soluções de problemas e dos avanços e recuos das ações dos missionários presbiterianos norte-americanos na área sob sua jurisdição.

Os missionários presbiterianos refletiam a crença do povo norte-americano na educação e na sua força moral, uma constante em toda a história dos Estados Unidos. Resultado da força da tradição da ética protestante, principalmente da puritana, a educação era importante para a salvação da alma e para a prosperidade da comunidade, pois para eles, a prosperidade não se alcança com um povo ignorante e pobre. A riqueza individual e a 
prosperidade da comunidade eram os meios para que a família comunitária tivesse condições de honrar dignamente a Deus, e o trabalho era o instrumento principal para que isso ocorresse. Daí, a importância dada ao preparo dos jovens para o trabalho produtivo, desenvolvendo o agudo sentido do pragmatismo vivencial que sempre caracterizou a cultura norte-americana.

O sistema escola-fazenda implantado na fazenda Ponte Nova, onde fora construída a escola, consistia numa política de autosustentação, introjetando no alunado o princípio da prática como instrumento do conhecimento e critério da verdade. O método adotado no Instituto Ponte Nova inseria os jovens no mundo do trabalho e apontava a pretensão de higienizar a sociedade através da educação. O sistema de auto-sustento funcionava em duplo sentido. Semelhante àquele colégio, as escolas primárias e os internatos, distribuídos na área sob a jurisdição da Missão Central do Brasil, adotavam o mesmo modelo de auto-governo, buscando sua sustentação financeira no local em que estavam inseridas, formando a futura população evangélica para suas igrejas e, conseqüentemente, dando suporte humano ao Instituto Ponte Nova, enviando alunos que completariam seus estudos, a maioria dos quais retornaria ao seu local de origem, funcionando como agentes irradiadores do modelo pedagógico presbiteriano.

Durante cem anos - 1871 a 1971 - os missionários vinculados à Missão Central do Brasil, partindo da Bahia, organizaram igrejas, escolas e hospitais em sua área de jurisdição. O Instituto Ponte Nova, instituição de ensino secundário rural, ofereceu durante décadas inicialmente os cursos normal, preparatório de pastores, e, anos depois, auxiliar de enfermagem e técnico agrícola. Após a saída da Missão, aquela escola foi nacionalizada e integrada à Rede Pública Estadual da Bahia. Os cursos formadores de técnicos agrícolas e de auxiliares de enfermagem foram oferecidos até 1999 e o normal continua funcionando até os dias atuais. Em 1956, foi criado, dentro da estação missionária Ponte Nova, o Instituto Bíblico Waddell. Com a duração de dois anos, o curso tinha como finalidade capacitar professoras do Instituto Ponte Nova e enfermeiras da Escola de Enfermagem para iniciarem congregações, denominados de pontos de pregação, escolas dominicais, ou auxiliar nos trabalhos já existentes no sertão baiano. Na década de 1970, o Grace Memorial Hospital foi transferido para o serviço público do Estado da Bahia. 
Mesmo sabendo que o documento é o resultado da construção de uma realidade feita por homens, estes mesmos homens deixam pistas, rastros, traços, pequenas impressões que escapam do seu controle, as quais são "marcas digitais ou sulcos de formão que podem ser detectados por um perito", possibilitando reconstruir conformações/representações culturais de determinada sociedade. (ECO; SEBEOK, 1991, p. 44). O pesquisador não pode esquecer-se ao avaliar as provas que, "todo ponto de vista sobre a realidade, além de ser intrinsecamente seletivo e parcial, depende das relações de força que condicionam, por meio da possibilidade de acesso à documentação, a imagem total que uma sociedade deixa de si". (GINZBURG, 2002, p. 43)

Este trabalho espera ter contribuído na elucidação de algumas práticas civilizatórias implementadas por um grupo presbiteriano norte-americano presente no interior da Bahia. Há muito ainda a pesquisar a respeito da atuação do Instituto Ponte Nova no cenário educacional baiano. Mesmo não sendo possível fazer aqueles sujeitos falarem, poder-se-á falar em seu lugar, das realidades de sua época, de suas intenções e ações, assim como das intenções e ações que facultaram o desconhecimento de sua existência na historiografia educacional brasileira. Necessário se faz investigar mais amiúde a formação de várias gerações de professores, pastores, enfermeiros e técnicos agrícolas, propagadores daquele padrão cultural norte-americano - o presbiteriano.

\title{
North Americans in Bahia: the civilizing project of the Presbyterian missionaries
}

\begin{abstract}
This work analyzes the civilizating Presbyterian action, searching to understand the importance of the Bahia for the North American missionaries as locus of its performance in the region under its jurisdiction. It investigates the importance of the Ponte Nova Institute and the Grace Memorial Hospital for the formation of pictures in the fields of the education, health and indoctrination, becoming a polar broadcast of a North American cultural model. KEY WORDS: Presbyterian Church. Instituto Ponte Nova - Chapada Diamantina (BA). Missionaries - United States.
\end{abstract}

\section{Referências}

BASTIAN, Jean-Pierre. Protestantismos y modernidad latinoamericana: historia de unas minorías religiosas activas en América Latina. México: Fondo de Cultura Económica, 1994. 
CENTRAL BRAZIL MISSION. Minutes of the meetings of the Central Brazil Mission, 1904-1938. Vitória: [s.n], 1938. Arquivo particular de James Wright

ECO, Umberto; SEBEOK, Thomas A. (Org.). O signo de três: Dupin, Holmes, Peirce. São Paulo: Perspectiva, 1991.

ELIAS, Norbert. A sociedade dos indivíduos. Rio de Janeiro: J. Zahar, 1994.

GINZBURG, Carlo. Relações de força: história, retórica, prova. São Paulo: Companhia das Letras, 2002.

LAGUNA, Shirley P. Reconstrução histórica do curso normal da Escola Americana de São Paulo (1889-1933).: internato de meninas: uma leitura de seu cotidiano e da instrução e educação feminina aí ministradas. 1999. Dissertação (Mestrado em Educação) - Pontifícia Universidade Católica de São Paulo.

NASCIMENTO, Ester Fraga Vilas-Bôas Carvalho do. Educar, curar, salvar: uma ilha de civilização no Brasil Tropical. 2005a. Tese (Doutorado em Educação) - Pontifícia Universidade Católica de São Paulo.

Os missionários da educação e o Instituto Ponte Nova. Revista Lusófona de Educação, Lisboa, n. 5, p. 111-126, 2005b.

A influência da pedagogia norte-americana em Sergipe e na Bahia: reflexões iniciais. Revista Brasileira de História da Educação, Campinas, n. 2, p. 9-38, jul/dez. 2001.

A Escola Americana: origens da educação protestante em Sergipe (1886-1913). São Cristóvão: Grupo de Estudos em História da Educação/NPGED/UFS, 2004.

O PURITANO, São Paulo: Arquivo Histórico Presbiteriano, 1907.

UNITED STATES OF AMERICA. PRESBYTERIAN BOARD OF FOREING MISSIONS. Grace Memorial Hospital. [S.1.: s.n.], 1936.

VIÑAO FRAGO, Antonio; ESCOLANO, Agustín. Currículo, espaço e subjetividade: a arquitetura como programa. Rio de Janeiro: DP\&A, 1998.

WHELLER, Reginald. Modern missions in Chile and Brazil. Philadelphia: The Westminster Press, 1926. 